\title{
Identifying Potential Clues On Covid-19 Through Coronavirus-Related Literature Using A Data-Driven Approach With The Help Of A Text Mining-Based Software, PredictSearch.
}

\author{
Angela Patatian' ${ }^{1}$ and Philippe Benech ${ }^{2 *}$ \\ ${ }^{1}$ Laboratoire GENEX, 1 chemin du Saulxier Lonjumeau, 91160 France \\ ${ }^{2}$ Aix-Marseille Univ., CNRS, INP, Inst. of Neurophysiopathol, Marseille France \\ DOI: 10.29322/IJSRP.10.09.2020.p10560 \\ http://dx.doi.org/10.29322/IJSRP.10.09.2020.p10560
}

\begin{abstract}
Huge amounts of scientific publications are produced daily in particular in many fields of medicine and biological science. Managing these data and deducing valuable information to identify significant clues to understand a physiological or pathological mechanism as well as to propose therapeutic solutions are urgently needed. Here we describe the use of a dedicated text mining-based software, PredictSearch (PS) to explore, through a literature survey, significant correlations between terms related to coronavirus infection. Our search highlighted some features of antiviral compounds such as chloroquine and glycyrrhizin and their impacts on apoptotic cell death, cell cycle and endocytic pathway in the course of coronavirus infection. In addition, the reported mechanisms through which the virus can avoid the interferon-induced antiviral state should pave the way to identify efficient therapies. This study demonstrates the importance of informatics tools such as PredictSearch dedicated to scientific literature survey to adapt previous knowledge to new health issues on a particular topical subject like Covid-19 pandemia.
\end{abstract}

Index Terms- SARS-CoV2, literature search, text mining

\section{BRIEF PREDICTSEARCH DESCRIPTION}

$\mathrm{P}^{\mathrm{s}}$ $S$ allows determining links between biological terms and/or molecules (genes, proteins, metabolites, chemical compounds) within title/abstracts of publications of the PubMED database. Title or abstracts quoting at least one gene were all collected as at the beginning, its main use was to decipher the impact of gene modulation evaluated by transcriptomic analysis (microarray). Then, these titles/abstracts were submitted to text mining through an anti-dictionary that removes terms not biologically relevant or, taken alone, too general such as "repair", "synthesis", "expression", "DNA", "protein", "cells"... However, these terms were stored in a specialized data base named "generic words" within a specific dictionary. Moreover our anti-dictionary preserves meaningful concepts defined as a series of terms, even those including "generic words" (e.g. "interferon expression", "DNA repair"). Iterative searches start by dropping within our working window either one or several genes of our gene data base (right panel in figure 1) or a particular term/concept using the "Search" tab (left panel in figure1). The "Annotate" tab allows to see all the terms/concepts (either classified by $p$-value, number of publications or alphabetical order) correlated with the term(s)/gene(s) selected in the working window. Like for genes, each of these terms found in either one or all dictionaries can be dropped into the working window and new correlation searches with these added terms can be performed. At the bottom of the screen, the "Abstracts" tab lists all the publications in which selected terms are co-cited.

\section{ANTIVIRAL MOLECULES RELATED TO CORONAVIRUS}

In the present study, we choose two key words as baits: "coronavirus" and "antiviral" (Fig.1). At first, selecting only "coronavirus" led to the identification of 2704 words present in dictionaries encompassing terms of biological process, "customizable words" (issued from biological dictionaries), generic words, composed words (series of words) and key words (all terms that were not retained by the anti-dictionary and absent in the other dictionaries). Adding the term "antiviral" reduced the number of words to 185 (Fig.1). Among those exhibiting a p value $<0,05$, in addition to angiotensin ( $p$ value $=3 \mathrm{e}-03$ ) and interferon $(p$ value $=1 \mathrm{e}-02)$, the top thirty words contained chemical or herbal compounds such as "glycyrrhizin" ( $p$ value $=3 e-06$ ), "PLPRO" (papain-like protease, $p$ value $=8 \mathrm{e}-05), 6$-azauridine $(\mathrm{p}$ value $=4 \mathrm{e}$ $04)$, nelfinavir ( $p$ value $=4 \mathrm{e}-03$ ), and chloroquine $(\mathrm{p}$ value $=2 \mathrm{e}-02)$. In order to avoid missing publications that did not contain a gene name, search for title/abstracts citing a combination of the selected terms was performed on all PubMed. Noteworthy, glycyrrhizin, nelfinavir, chloroquine were all co-cited in a study of 2006 launched to evaluate several potential antivirals against SARS coronavirus infections (1).

Selecting "coronavirus", "antiviral" and "glycyrrhizin" led to 6 publications $(1,2,3,4,5,6)$. Glycyrrhizin is one of the constituents of glycyrrhiza glabra (liquorice) root. Animal and in vitro studies demonstrated a reduction of viral activity in herpes simplex virus encephalitis and influenza A virus pneumonia, and revealed antiviral activity against HIV-1, SARS related coronavirus, respiratory syncytial virus, arboviruses and vesicular 
stomatitis virus. Of different compounds (ribavirin, 6-azauridine, pyrazofuridin or mycophenolic acid), glycyrrhizin was the most active in inhibiting replication of the SARS-associated virus (6). 6-azauridin was cited only in the title/abstract of two more publications (7, 8). While a search for "nelfinavir" with "coronavirus" and "antiviral" identified 4 publications $(1,9,10$, 11), 27 publications were found quoting in their titles/abstracts our baits and "chloroquine". Moreover, 15 were published in 2020, none in 2019, but no more than one per year was listed for the period between 2003 and 2018. The earliest report in 2003 (12) was focused on the observation that astrocytes were the major targets for mouse hepatitis virus (MHV) persistence. It showed also that expression of the pro-apototic Bnip3 gene was reduced following $\mathrm{MHV}$ infection and that chloroquine significantly inhibited the repression of Bnip3 promoter activity induced by the acidic-pH dependent MHV mutant OBLV60 (Fig.2). The next publication in 2004 (13) reported that chloroquine phosphate induced a significant antiviral activity in vitro in cells infected with the severe acute respiratory syndrome coronavirus (SARS$\mathrm{CoV})$.

\section{CHLOROQUINE ACTIVITIES}

The first publication mentioning a therapeutic effect of chloroquine phosphate on COVID-19 patients appeared on March 2020 (14). The same month, two other publications evaluated the use of chloroquine against COVID-19. One can be considered as the first evidence that hydroxychloroquine was more potent than chloroquine to inhibit SARS-CoV-2 in vitro (15). The second reviewed the different activities involved in the antiviral activity of chloroquine (16). This last publication prompted us to add to our query, terms like: "quinone reductase"; "sialic acid"; "alkalinization"; "endosome"; "glycosylation" and "p38 MAPK" using the search tab.

Keeping chloroquine as the common bait, a search for terms correlated with "endosome" led to indentify 2407 terms, with "glycosylation" 665, with "syalic acid" 201 and with "alkalinization" 196. The most significant gene shared among all these terms was NEU1 (neuraminidase 1), which codes for a lysosomal enzyme that cleaves terminal sialic acid residues from substrates such as glycoproteins and glycolipids. Interestingly, "neuraminidase" was also co-cited with "coronavirus" in 48 publications (the earliest being published in 1976). Neuraminidase inhibitors are a class of drugs that block the viral neuraminidase enzyme of the influenza virus by preventing its budding from the host cell (17).

Genes that were cited with either "coronavirus", "glycyrrhizin" and "chloroquine" led separately to 609, 503 and 2001 genes, respectively. However, only few genes were co-cited with at least two of these terms.

CASP8 (caspase 8) encodes a member of the cysteineaspartic acid protease (caspase family). This protein is involved in programmed cell death (apoptosis) induced by various apoptotic stimuli such as stress triggered by UV irradiation, reactive oxygen species (ROS), but also by bacterial or viral infection. CASP8 was one of the caspases activated by canine coronavirus $(\mathrm{CCOV})$ and this activation results in apoptosis (18). Similarly, apoptosis together with CASP8 activity was increased in cells infected with the equine coronavirus (19). However, glycyrrhizin was reported to induce apoptosis through CASP8 activation and TP53 increase (20)

CTSB (cathepsin B) encodes a member of the C1 family of peptidases. One proteic product generated by this gene is a lysosomal cystein protease with both endopeptidase and exopeptidase activity that may play a role in protein turnover. It has been shown that the ability of different strains of feline coronavirus to infect cells were highly dependent of host cell CTSB activity for entry into the host cell as well as on the low $\mathrm{pH}$ of endocytic compartments (21). It was suggested that host cell cathepsins may play a role in the distinct tropisms displayed by different feline coronavirus biotypes. An inhibition of CTSB expression and a stabilization of lysosomal membranes by the biologically active metabolite of glycyrrhizin, 18betaglycyrrhetinic, which can prevent free fatty acid-induced lipid accumulation and cell apoptosis in vitro, were observed (22).

$B C L 2$ ( $\mathrm{Bcl} 2$ apoptosis regulator) encodes an integral outer mitochondrial membrane protein that blocks the apoptotic cell death. It has been shown that canine coronavirus type II decreased $\mathrm{Bcl} 2$ expression in cytosol (23). Moreover, expression of the SARS-CoV nucleocapsid (SARS-CoV N) protein was reported to down-regulate BCL2 levels and to induce apoptosis (24). On the other hand, Parris (25) proposed an interesting hypothesis that linked BCL2, chloroquine and coronavirus. Indeed, chloroquine facilitates apoptosis of abnormally persistent $\mathrm{T}$-cell clones by suppressing NF-kappa-B, which enhances the expression of antiapoptotic proteins such as BCL2. Based on this observation, one may hypothesize that prophylactic exposure to pro-apoptotic chloroquine drugs caused natural selection for strains of viruses and other parasites that have enhanced anti-apoptotic abilities. Hence, drugs that suppress BCL2 or restore TP53 function might be effective in restoring the parity of resistance to apoptosis between infected and uninfected cells. Similarly to chloroquine, 18beta-glycyrrhetinic acid can induce apoptotic cell death at least in part through reducing BCL2 level (26).

TP53 encodes a transcriptional factor that responds to various cellular stresses to regulate expression of target genes resulting in cell cycle arrest, apoptosis, senescence, DNA repair, or changes in metabolism. Although apoptosis induced by coronavirus infectious bronchitis virus was shown to be independent of TP53, infection imposed a growth-inhibitory effect on cultured cells by inducing a cell cycle arrest at S and G(2)/M phases (27). However, depending on the cellular models, an activation of TP53 pathway and a suppression of cell growth by chloroquine were reported (28).

Furthermore, chloroquine and hydroxychloroquine were also known as potent inhibitors of autophagy, a process that performs the self-digestion of damaged cells to generate ATP and other essential biosynthetic molecules to temporarily avoid cell death (29). In addition to raise the lysosomal $\mathrm{pH}$ (30), chloroquine may block the fusion between autophagosomes and lysosomes through its ability to disorganize golgi and endosomal systems (31). Autophagy inhibition induces an endoplasmic reticulum stress that in turn initiates apoptosis (Fig. 2). Although in the case of viral infection, autophagy can be either proviral or antiviral (32, 33), it was shown that the viral nsp6 protein of different coronaviruses including severe acute respiratory syndrome virus activates autophagy (34). Although like apoptosis, autophagy can be considered as an antiviral defense at the early step of viral 
infection, viruses can subvert and exploit, later on, multiple steps of the autophagic pathway to evade immune responses and facilitate viral replication (reviewed in 35). It has been demonstrated that autophagy is required for the formation of complexes resulting from the binding of coronavirus hepatitis virus (MHV) to double membrane vesicles (DMVs) and that DMV formation significantly enhances the efficiency of the virus replication (36). However, MHV replication or release might depend neither on the autophagic factor ATG-5, by which cells deliver DMVs containing cytoplasm or cytoplasmic organelles to the lysosome, nor on an intact autophagic pathway (37). The controversial involvement of autophagy in viral replication may depend on the type of viruses used or cells tested as well as on the different techniques used in studying autophagy.

Nevertheless, autophagosomes that are produced during autophagy fuse with the endosomal pathway (Fig. 2). The endocytic pathway is used for CoVs to enter host cell towards the participation of the subunit viral protein S2 (38). The first publication co-citing "coronavirus" and "endocytic pathway" appeared in 2001 (39) and concerned the human coronavirus HcoV-229E. Since then, several studies have firmly established the role of the endocytic pathway in controlling the virus entry into the host cell.

\section{IMPACTS OF SARS-COV/ACE2 INTERACTION}

It has been reported that chloroquine, known to inhibit acidification of endosomes during the events of replication and infection (15), exhibited an antiviral effect either before or after exposure to SARS-CoV through interfering with terminal glycosylation of the cellular receptor, angiotensin-converting enzyme 2 (ACE2). From 325 PubMed reports containing "SARSCoV" and "angiotensin-converting enzyme", 155 were published up to the end of April 2020. ACE2, expressed in a variety of tissues including both the upper and lower respiratory tract, myocardium and the gastrointestinal mucosa (40), is the main receptor for coronavirus entry into cells (Fig. 3). Moreover, SARS-CoV2 may also infect endothelial cells (41), which indeed express ACE2 (42). The TNF-alpha converting enzyme (TACE) activated by the spike protein of SARS-CoV (SARS-S protein) was found to promote ACE2 ectodomain shedding (Fig. 3), and therefore the entry of SARs-CoV as well as TNF production (43). Loss of ACE2 that is translocated from the cell surface to endosomes after binding to the SARS-S protein, might lead to several deleterious events (Fig. 3). While ACE2 exhibits antiinflammatory activity, ACE2 deficiency results in vascular inflammation and an inflammatory response that contributes to atherosclerotic plaque formation (44). These events relied on the activity of ACE2, which is involved in the conversion of angiotensin 1 into angiotensin 1-9 and production of the vasodilatator 1-7 angiotensin from angiotensin 2. Indeed, ACE2 can block its homolog ACE inhibiting the conversion of angiotensin 1 into angiotensin 2 (Fig. 3). Loss of ACE2 will therefore lead to an increase of angiotensin 2 and as a consequence to vasoconstriction, elevation of blood pressure and ROS production through NADPH oxidase activation (45). It can be speculated that at the site where vasoconstriction occurs, TNF release and/or atherosclerotic plaque inducing inflammatory cytokines will trigger endothelial barrier dysfunction. Disruption of the endothelial barrier will affect pulmonary alveoli, required for gas exchange causing ultimately acute respiratory distress syndrome (ARDS), a syndrome that is known to be the main cause of the mortality of SARS-CoV 2 infected patients. Moreover, pulmonary infection with the human SARS-CoV in mice led to an ACE2-dependent myocardial infection with a mark decrease in ACE2 expression (46), which, as described above, will result in deleterious effects due to angiotensin 2 accumulation (Fig.3).

\section{INTERFERON PATHWAY AND CORONAVIRUS INFECTION}

The endocytic pathway may be even more important in our understanding of the CoVid-19 syndrome considering it can be associated with IFN resistance (Fig. 4). Tan et al. (47) tested several drugs in culture for their antiviral ability against SARS$\mathrm{CoV}$, including neuraminidase inhibitors and showed complete inhibition of cytopathic effects for some interferon (IFN) subtypes and human leukocyte interferon- $\alpha$.

However, it was well established that SARS-CoV employs multiple passive and active mechanisms to avoid induction of type I interferons in cells. Loss of an efficient IFN response is likely to contribute to the establishment of a viremia early in infection. By contrast, high secretion of chemokines such as IP-10 and IL-8 might be responsible for massive immune cell infiltrations found in the lung of infected patients and the dysregulation of adaptive immunity (48).

Coronavirus can evade from the IFN system through several distinct mechanisms. Indeed, the antiviral effect of IFN relies in part on the expression of the 2'-5' Oligo adenylate synthetase (OASE). This enzyme, once activated by double strand (ds) RNAs, synthesizes 2'-5' oligo adenylates (2'-5'A), which as dimers or tetramers stimulate the dsRNA dependent-RNase L leading to the degradation of cytoplasmic and viral RNAs (Fig. 4). However several viruses exhibit a 2'-5' phosphodiesterase-like activity such as the viral protein ns2 of the coronavirus MHV, which confers virulence by cleaving $2^{\prime}-5$ ' A resulting in no activation of Rnase $\mathrm{L}(49,50)$. In addition to the viral inhibition of the $2^{\prime}-5$ 'A/Rnase $\mathrm{L}$ system, it was shown that in SARS-CoV infected fibroblasts, no detectable induction of IFN- $\beta$ occurs $(51$, $52,53)$.

On the other hand, it was reported that absence of IFN$\beta \square$ results from the loss of activation of IRF3 (IFN regulatory factor 3 ), which is essential for IFN- $\beta \square$ production (54). IRF3 synthesis is achieved through the combined activities of different factors (RING-1, MDA-5, PKR) activated in response to 5 'triphosphorylated single stranded (ss) RNA or dsRNA (Fig. 4). It was suggested that loss of IRF3 might result from the impaired sensing of coronavirus by pathogen recognition receptors (PRRs) such as TLRs (Toll like receptors). One hypothesis was that dsRNA replication intermediates are located within the double membrane vesicles whose formation are induced, as we mentioned earlier, by virus infection and consequently will be protected from PRR sensing (54). Noteworthy, in contrast to coronavirus RNA, sensing with the IFN-inducer poly (I:C), polyinosinic:polycytidylic acid, a syntethic double strand RNA, resulted in IFN- $\beta$ transcription and intranasal treatment with poly (I:C) was found to protect aged mice from lethal respiratory virus infections (55). It has to be noticed that whereas myeloid dentritic 
cells (mDCs) and fibroblasts failed to produce IFN, plasmacytoid cells (pDCs) in the course of MHV infection are able to produce type I IFNs towards TLR7 (56). Noteworthy, elderly women had reduced number of $\mathrm{pDCs}$ and reduced TLR7/8 response compared to young adults (57). In contrast, seric markers involved in inflammation were increased in elderly and high levels of IL-6 correlated with increased morbidity and mortality were observed (58). Altogether these results are reminiscent of the observations that elderly with Covid-19 disease were indeed more prone in a context of a cytokine storm to respiratory illnesses resulting in higher mortality rates in such a population.

\section{CONCLUSIVE REMARKS}

Investigating associated terms with "coronavirus" and "antiviral", PredictSearch allowed to identify within the literature several antiviral drugs or biological molecules including chloroquine and glycyrrhizin. Iterative queries highlighted different processes that might suggest how the virus can counteract at an early step the cellular defenses. Indeed, modulation of cell growth and induction of apoptosis are two common strategies used by many viruses to regulate their infection cycles. As other viruses, coronavirus infection leads at first to the induction of a cellular stress in the host cell. This stress has to be considered as a protective response of the host cell to avoid virus propagation through the induction of cell growth arrest and apoptosis. However, we report a hypothesis to explain how cellular resistance to apoptotic cell death might allow selecting some cells to survive and to constitute an important virus reservoir after cell recovery. It is suggested that the anti-viral activity of chloroquine or glycyrrhizin relies in part on their ability to induce apoptosis of the infected cells that were selected to survive. However this apoptosis will be triggered by events distinct from those induced at first by the viral stress. For instance, chloroquine can induce lysosomal stress and provoke a TP53-dependent cell death that does not require caspase-mediated apoptosis (59). Therefore, according to the inhibitory effect of chloroquine on autophagy and its ability to induce apoptosis, the benefit of the treatment should be considered in a time window when the virus alters these events for its survival and spread. The resulting impact of chloroquine on autophagy should also reduce not only the viral induced formation of cytoplasmic vesicles such as DMVs but also provoke alkalinization of these subcellular structures leading to the degradation of viral RNA replication intermediates. Moreover, localization of these intermediates within DMVs avoids viral sensing, an event crucial for an induced IFN expression in different cell types with the exception of $\mathrm{pDCs}$, which are reduced in elderly. It can be speculated that to bypass the reduced expression of IFN in the course of coronavirus infection, use of poly (I/C) that in contrast to dsRNAs induces IFN expression, can be a therapeutic option in combination with an anti-IL6 treatment. Other factors downstream of IFN can also be proposed to provide an antiviral state such as 2 '-5'A that can be combined with poly (I/C) together with an inhibitor of 2'-5' phosphodiesterase activity of the viral ns2 protein to avoid 2'-5'A degradation and Rnase L inactivation.

Thus, we believed that the correlations found by PredictSearch analysis based on existing knowledge might highlight important tracks to speed the identification of therapeutic approaches helping to fight new syndromes like Covid-19. More generally, this work illustrates how dedicated computational tools respond to the urgent need to deal with an exponential increase of publications.

\section{ACKNOWLEDGMENTS}

We are indebted to Dr. Michel Khrestchatisky for critically reading the manuscript and to Genex Laboratories that provided a free access to PredictSearch.

\section{CONFLICTS OF INTEREST}

The authors declare no conflict of interest

\section{REFERENCES}

[1] De Clercq E. Potential antivirals and antiviral strategies against SARS coronavirus infections Expert Rev Anti Infect Ther. 2006 Apr;4(2):291-302. DOI: 10.1586/14787210.4.2.291.

[2] Pu JY, He L, .Wu SY, Zhang P, Huang X. Anti-virus research of triterpenoids in licorice. Bing Du Xue Bao. 2013 Nov;29(6):673-9.

[3] Fiore C, Eisenhut M, Krausse R, Ragazzi E, Pellati D, Armanini D, Bielenberg J. Antiviral effects of Glycyrrhiza species. Phytother Res. 2008 Feb;22(2):141-8. DOI: 10.1002/ptr.2295.

[4] Hoever G1, Baltina L, Michaelis M, Kondratenko R, Baltina L, Tolstikov GA, Doerr HW, Cinatl J Jr. Antiviral activity of glycyrrhizic acid derivatives against SARS-coronavirus. J Med Chem. 2005 Feb 24;48(4):1256-9. DOI: 10.1021/jm0493008.

[5] Chen F1, Chan KH, Jiang Y, Kao RY, Lu HT, Fan KW, Cheng VC, Tsui WH, Hung IF, Lee TS, Guan Y, Peiris JS, Yuen KY. In vitro susceptibility of 10 clinical isolates of SARS coronavirus to selected antiviral compounds. J Clin Virol. 2004 Sep;31(1):69-75.DOI: 10.1016/j.jcv.2004.03.003.

[6] Cinatl J, Morgenstern B, Bauer G, Chandra P, Rabenau H, Doerr HW Glycyrrhizin, an active component of liquorice roots, and replication of SARS-associated coronavirus. Lancet. 2003 Jun 14;361(9374):2045-6. DOI:10.1016/s0140-6736(03)13615-X

[7] Pyrc K, Bosch BJ, Berkhout B, Jebbink MF, Dijkman R, Rottier P, van der Hoek L. Inhibition of human coronavirus NL63 infection at early stages of the replication cycle. Antimicrob Agents Chemother. 2006 Jun;50(6):20008.DOI: 10.1128/AAC.01598-05.

[8] Barlough JE, Shacklett BL. Antiviral studies of feline infectious peritonitis virus in vitro. Vet Rec. 1994 Aug 20;135(8):177-9. DOI: 10.1136/vr.135.8.177

[9] Chan JF, Chan KH, Kao RY, To KK, Zheng BJ, Li CP, Li PT, Dai J, Mok FK, Chen H, Hayden FG, Yuen KY. Broad-spectrum antivirals for the emerging Middle East respiratory syndrome coronavirus. J Infect. 2013 Dec;67(6):606-16. DOI: 10.1016/j.jinf.2013.09.029.

[10] Hsieh LE, Lin CN, Su BL, Jan TR, Chen CM, Wang CH, Lin DS, Lin CT, Chueh LL. Synergistic antiviral effect of Galanthus nivalis agglutinin and nelfinavir against feline coronavirus. Antiviral Res. 2010 Oct;88(1):25-30. DOI: 10.1016/j.antiviral.2010.06.010.

[11] Yamamoto N, Yang R, Yoshinaka Y, Amari S, Nakano T, Cinatl J, Rabenau H, Doerr HW, Hunsmann G, Otaka A, Tamamura H, Fujii N, Yamamoto N. HIV protease inhibitor nelfinavir inhibits replication of SARS-associated coronavirus. Biochem Biophys Res Commun. 2004 Jun 4;318(3):71925.DOI: 10.1016/j.bbrc.2004.04.083.

[12] Cai Y, Liu Y, Yu D, Zhang X. Down-regulation of transcription of the proapoptotic gene BNip3 in cultured astrocytes by murine coronavirus infection. Virology. 2003 Nov 10;316(1):104-15.DOI: 10.1016/j.virol.2003.07.007.

[13] Keyaerts E, Vijgen L, Maes P, Neyts J, Van Ranst M. In vitro inhibition of severe acute respiratory syndrome coronavirus by chloroquine. Biochem Biophys Res Commun. 2004 Oct 8;323(1):264-8.DOI: 10.1016/j.bbrc.2004.08.085. 
[14] ZhonghuaJie $\mathrm{He} \mathrm{He} \mathrm{Hu} \mathrm{Xi} Z \mathrm{Za}$ Zhi. Expert consensus on chloroquine phosphate for the treatment of novel coronavirus pneumonia; $2020 \mathrm{Mar}$ 12;43(3):185-188. DOI: 10.3760/cma.j.issn.1001-0939.2020.03.009.

[15] Vincent MJ, Bergeron E, Benjannet S, Erickson BR, Rollin PE, Ksiazek TG, Seidah NG, Nichol ST. Chloroquine is a potent inhibitor of SARS coronavirus infection and spread. Virol J. 2005 Aug 22;2:69. DOI: 10.1186/1743-422X-2-69.

[16] Devaux CA, Rolain JM, Colson P, Raoult D. New Insights on the Antiviral Effects of Chloroquine Against Coronavirus: What to expect for COVID-19? Int J Antimicrob Agents. 2020 Mar 12;105938. DOI: 10.1016/j.ijantimicag.2020.105938.

[17] McAuley JL, Gilbertson BP, Trifkovic S, Brown LE, McKimm-Breschkin JL. Influenza Virus Neuraminidase Structure and Functions. Front Microbiol. 2019; 10: 39.2019 Jan 29. doi: 10.3389/fmicb.2019.00039

[18] De Martino L, Marfé G, Longo M, Fiorito F, Montagnaro S, Iovane V, Decaro N, Pagnini U. Bid Cleavage, Cytochrome C Release and caspase activation in canine coronavirus-Induced apoptosis. Vet Microbiol. $2010 \mathrm{Feb}$ 24;141(1-2):36-45. DOI: 10.1016/j.vetmic.2009.09.001.

[19] Suzuki K, Matsui Y, Miura Y, Sentsui H. Equine coronavirus induces apoptosis in cultured cells. VetMicrobiol. 2008 Jun 22;129(3-4):390-5. DOI: 10.1016/j.vetmic.2007.11.034

[20] Soo Lee C, Yang JC, Kim YJ, Jang E-R, Kim W, Myung SC. 18 $\beta$ Glycyrrhetinic acid potentiates apoptotic effect of trichostatin A on human epithelial ovarian carcinoma cell lines. Eur J Pharmacol. 2010 Dec 15;649(13):354-61. DOI: 10.1016/j.ejphar.2010.09.047.

[21] Regan AD, Shraybman R, Cohen RD, Whittaker GR. Differential role for low $\mathrm{pH}$ and cathepsin-mediated cleavage of the viral spike protein during entry of serotype II feline coronaviruses.Vet Microbiol. 2008 Dec 10;132(34):235-48. DOI: 10.1016/j.vetmic.2008.05.019.

[22] Wu X, Zhang L, Gurley E, Studer E, Shang J, Wang T, Wang C, Yan M, Jiang Z, Hylemon PB, Sanyal AJ, Pandak Jr WM, Zhou H. Prevention of free fatty acid-induced hepatic lipotoxicity by 18 beta-glycyrrhetinic acid through lysosomal and mitochondrial pathways. Hepatology. 2008 Jun;47(6):190515. DOI: $10.1002 /$ hep. 22239

[23] Marfè G, Tafani M, Fiorito F, Pagnini U, Iovane G, De Martino L. Involvement of FOXO transcription factors, TRAIL-FasL/Fas, and Sirtuin proteins family in canine coronavirus Type II-induced apoptosis. PLoS One. 2011;6(11):e27313. DOI: 10.1371/journal.pone.0027313.

[24] Surjit M, Liu B, Jameel S, Chow VTK, Lal SK; The SARS Coronavirus nucleocapsid protein induces actin reorganization and apoptosis in COS-1 Cells in the absence of growth factors. Biochem J. 2004 Oct 1;383(Pt 1):138. DOI: $10.1042 / \mathrm{BJ} 20040984$

[25] Parris GE. Hypothesis links emergence of Chloroquine-resistant malaria and other intracellular pathogens and suggests a new strategy for treatment of diseases caused by intracellular parasites. Med Hypotheses. 2004;62(3):3547. DOI: $10.1016 /$ j.mehy.2003.12.004.

[26] Soo Lee CS , Kim YJ, Lee MS, Han ES, Lee SJ. 18beta-glycyrrhetinic acid induces apoptotic cell death in $\mathrm{SiHa}$ cells and exhibits a synergistic effect against antibiotic anti-cancer drug toxicity. Life Sci. 2008 Sep 26;83(1314):481-9. DOI: 10.1016/j.lfs.2008.07.014.

[27] Li FQ , Tam JP, Liu DX. Cell cycle arrest and apoptosis induced by the coronavirus infectious bronchitis virus in the absence of p53. Virology. 2007 Sep 1;365(2):435-45. DOI: 10.1016/j.virol.2007.04.015.

[28] Kim EL,Wüstenberg R, Rübsam A, Schmitz-Salue C, Warnecke G, Bücker EM, Pettkus N, Speidel D, Rohde V, Schulz-Schaeffer W, Deppert W, Giese A. Chloroquine activates the p53 pathway and induces apoptosis in human glioma cells. Neuro Oncol. 2010 Apr;12(4):389-400. DOI: 10.1093/neuonc/nop046.

[29] Al-Bari MAA. Targeting endosomal acidification by chloroquine analogs as a promising strategy for the treatment of emerging viral diseases. Pharmacol Res Perspect. 2017 Jan 23;5(1):e00293. eCollection 2017 Feb. DOI: $10.1002 / \mathrm{prp} 2.293$

[30] Rutz M, Metzger J, Gellert T, Luppa P, Lipford GB, Wagner H, Bauer S. Toll-like receptor 9 binds single-stranded CpG-DNA in a sequence- and $\mathrm{pH}$ dependent manner. Eur J Immunol. 2004 Sep;34(9):2541-50. DOI: 10.1002/eji.200425218.

[31] Mauthe M, Orhon I, Rocchi C, Zhou X, Luhr M, Hijlkema K-J, Coppes RP, Engedal N, Mari M, Reggiori F. Chloroquine inhibits autophagic flux by decreasing autophagosome-lysosome fusion. Autophagy. 2018;14(8):14351455. DOI: $10.1080 / 15548627.2018 .1474314$.

This publication is licensed under Creative Commons Attribution CC BY http://dx.doi.org/10.29322/IJSRP.10.09.2020.p10560
[32] Levine B, Mizushima N, Virgin HW. Autophagy in immunity and inflammation. Nature. 2011 Jan 20;469(7330):323-35. DOI: 10.1038/nature09782.

[33] Jackson WT. Viruses and the autophagy pathway. Virology. 2015 May;479480:450-6. DOI: 10.1016/j.virol.2015.03.042.

[34] Cottam EM, Maier HJ, Manifava M, Vaux LC, Chandra-Schoenfelder P, Gerner W, Britton P, Ktistakis NT, Wileman T. Coronavirus nsp6 proteins generate autophagosomes from the endoplasmic reticulum via an omegasome intermediate. Autophagy. 2011 Nov;7(11):1335-47. DOI: 10.4161/auto.7.11.16642.

[35] Choi Y, Bowman JW, Jung JU. Autophagy during viral infection - A doubleedged sword. Nat Rev Microbiol. 2018 Jun;16(6):341-354. doi: 10.1038/s41579-018-0003-6.

[36] Prentice E, Jerome WG, Yoshimori T, Mizushima N, Denison MR Coronavirus replication complex formation utilizes components of cellular autophagy. J Biol Chem. 2004 Mar 12;279(11):10136-41. DOI: 10.1074/jbc.M306124200.

[37] Zhao Z, Thackray LB, Miller BC, Lynn TM, Becker MM, Ward E, Mizushima NN, Denison MR, Virgin 4th HW. Coronavirus replication does not require the autophagy gene ATG5. Autophagy. Nov-Dec 2007;3(6):5815. DOI: $10.4161 /$ auto.4782

[38] Millet JK, Whittaker GR. Physiological and molecular triggers for SARSCoV membrane fusion and entry into host cells. Virology. 2018 Apr;517:38. DOI: 10.1016/j.virol.2017.12.015.

[39] Blau DM, Holmes KV. Human coronavirus HCoV-229E enters susceptible cells via the endocytic pathway. Adv Exp Med Biol. 2001;494:193-8. DOI: 10.1007/978-1-4615-1325-4_31.

[40] Harmer D, Gilbert M, Borman R, Clark KL. Quantitative mRNA expression profiling of ACE 2, a novel homologue of angiotensin converting enzyme. FEBS Lett. 2002 Dec 4;532(1-2):107-10.DOI: 10.1016/s00145793(02)03640-2.

[41] Varga Z, Flammer AJ, Steiger P, Haberecker M, Andermatt R, Zinkernagel AS, Mehra MR, Schuepbach RA, Ruschitzka F, Moch H. Endothelial cell infection and endothelitis in COVID-19. Lancet. 2020 May 2;395(10234):1417-1418. DOI: 10.1016/S0140-6736(20)30937-5.

[42] Ferrario CM, Jessup J, Chappell MC, Averill DB, Brosnihan KB, Tallant EA, Diz DI, Gallagher PE. Effect of angiotensin-converting enzyme inhibition and angiotensin II receptor blockers on cardiac angiotensin-converting enzyme 2. Circulation. 2005 May 24;111(20):2605-10.

[43] Haga S Nagata N, Okamura T, Yamamoto N, Sata T, Yamamoto N, Sasazuki T, Ishizaka Y. TACE antagonists blocking ACE2 shedding caused by the spike protein of SARS-CoV are candidate antiviral compounds. Antiviral Res. 2010 Mar;85(3):551-5. DOI: 10.1016/j.antiviral.2009.12.001.

[44] Dennison CR, McEntee ML, Samuel L, Johnson BJ, Rotman S, Kielty A Russell SD. Adequate health literacy is associated with higher heart failure knowledge and self-care confidence in hospitalized patients. J Cardiovasc Nurs. 2011 Sep-Oct;26(5):359-67. DOI: 10.1097/JCN.0b013e3181f16f88.

[45] Patel VB1, Zhong JC1, Grant MB1, Oudit GY2. Role of the ACE2/Angiotensin 1-7 Axis of the Renin-Angiotensin System in Heart Failure. CircRes. 2016 Apr15;118(8):1313-26. DOI: 10.1161/CIRCRESAHA.116.307708.

[46] Oudit GY, Kassiri Z, Jiang C, Liu PP, Poutanen SM, Penninger JM, Butany J. SARS-coronavirus modulation of myocardial ACE2 expression and inflammation in patients with SARS. Eur J Clin Invest. 2009 Jul;39(7):61825. DOI: 10.1111/j.1365-2362.2009.02153.x.

[47] Tan ELC, Ooi EE, Lin C-Y, Tan HC, Ling AE, Lim B, Stanton LW. Inhibition of SARS coronavirus infection in vitro with clinically approved antiviral drugs. Emerg Infect Dis. 2004 Apr;10(4):581-6. DOI 10.3201/eid1004.030458.

[48] Thiel V, Weber F. Interferon and cytokine responses to SARS-coronavirus infection. Cytokine Growth Factor Rev. 2008 Apr;19(2):121-32. DOI: 10.1016/j.cytogfr.2008.01.001.

[49] Zhao L, Jha BK, Wu A, Elliott R, Ziebuhr J, Gorbalenya AE, Silverman RH, Weiss SR. Antagonism of the interferon-induced OAS-RNase L pathway by murine coronavirus ns2 protein is required for virus replication and liver pathology. Cell Host Microbe. 2012 Jun 14;11(6):607-16. DOI: 10.1016/j.chom.2012.04.011.

[50] Gusho E, Zhang R, Jha BK, Thornbrough JM, Dong B, Gaughan C, Elliott R, Weiss SR, Silverman RH. Murine AKAP7 has a 2',5'-phosphodiesterase domain that can complement an inactive murine coronavirus ns2 gene. mBio. 2014 Jul 1;5(4):e01312-14. DOI: 10.1128/mBio.01312-14. 
[51] Spiegel M, Pichlmair A, Martínez-Sobrido L, Cros J, García-Sastre A, Haller $\mathrm{O}$, Weber $\mathrm{F}$. Inhibition of Beta interferon induction by severe acute respiratory syndrome coronavirus suggests a two-step model for activation of interferon regulatory factor 3. J Virol. 2005 Feb;79(4):2079-86. DOI: 10.1128/JVI.79.4.2079-2086.2005.

[52] Versteeg GA, Slobodskaya O, Spaan WJM. Transcriptional profiling of acute cytopathic murine hepatitis virus infection in fibroblast-like cells. J Gen Virol. 2006 Jul;87(Pt 7):1961-75. DOI: 10.1099/vir.0.81756-0.

[53] Zhou H, Perlman S. Mouse hepatitis virus does not induce beta interferon synthesis and does not inhibit its induction by double-stranded RNA. J Virol. 2007 Jan;81(2):568-74. DOI: 10.1128/JVI.01512-06.

[54] Versteeg GA, Bredenbeek PJ, van den Sjoerd WHE, Spaan WJM. Group 2 coronaviruses prevent immediate early interferon induction by protection of viral RNA from host cell recognition. Virology. 2007 Apr 25;361(1):18-26. DOI: 10.1016/j.virol.2007.01.020.

[55] Zhao J, Wohlford-Lenane C, Zhao J, Fleming E, Lane TE, McCray Jr PB, Perlman S. Intranasal treatment with poly $(\cdot \bullet \mathrm{C})$ protects aged mice from lethal respiratory virus infections. J Virol. 2012 Nov;86(21):11416-24. DOI: 10.1128/JVI.01410-12.

[56] Cervantes-Barragan L, Züst R, Weber F, Spiegel M, Lang KS, Akira S, Thiel V, Ludewig B. Control of coronavirus infection through plasmacytoid dendritic-cell-derived type I interferon. Blood. 2007 Feb 1;109(3):1131-7. DOI: 10.1182/blood-2006-05-023770.
[57] van Splunter M, Perdijk O, Fick-Brinkhof H, Floris-Vollenbroek G, Meijer B, Brugman S, Savelkoul HFJ, van Hoffen E, van Neerven RJJ. Plasmacytoid dendritic cell and myeloid dendritic cell function in ageing: A Comparison between elderly and young adult women. PLoS One. 2019 Dec 12;14(12):e0225825. DOI: 10.1371/journal.pone.0225825.

[58] Franceschi C, Bonafè M, Valensin S, Olivieri F, De Luca M, Ottaviani E, De Benedictis G. Inflamm-aging. An evolutionary perspective on immunosenescence. Ann N Y Acad Sci. 2000 Jun;908:244-54. DOI: 10.1111/j.1749-6632.2000.tb06651.x

[59] Maclean KH, Dorsey FC, Cleveland JL, Kastan MB. Targeting lysosomal degradation induces p53-dependent cell death and prevents cancer in mouse models of lymphomagenesis. J Clin Invest. 2008 Jan;118(1):79-88. DOI: 10.1172/JCI33700.

\section{AUTHORS}

First Author - Angela Patatian, Laboratoire GENEX, 1 chemin du Saulxier Lonjumeau, 91160 France, a.patatian@laboratoiregenex.fr

Second Author - Philippe Benech, Aix-Marseille Univ., CNRS, INP, Inst. of Neurophysiopathol, Marseille France,

philippe.benech@univ-amu.fr

\section{Legends of figures:}

Figure 1: Screenshot capture of main PredictSearch features.

Figure 2: Schematic representation of the terms/concepts correlated to apoptosis, endocytic pathway, autophagy and coronavirus. Legends are indicated on the top right of the figure in a gray box.

Figure 3: Schematic representation of the terms/concepts correlated to ACE2 pathway and SARS-CoV infection. See figure 2 for legends.

Figure 4: Schematic representation of the terms/concepts correlated to interferon and viral infection. See figure 2 for legends. 


\section{Figure 1}

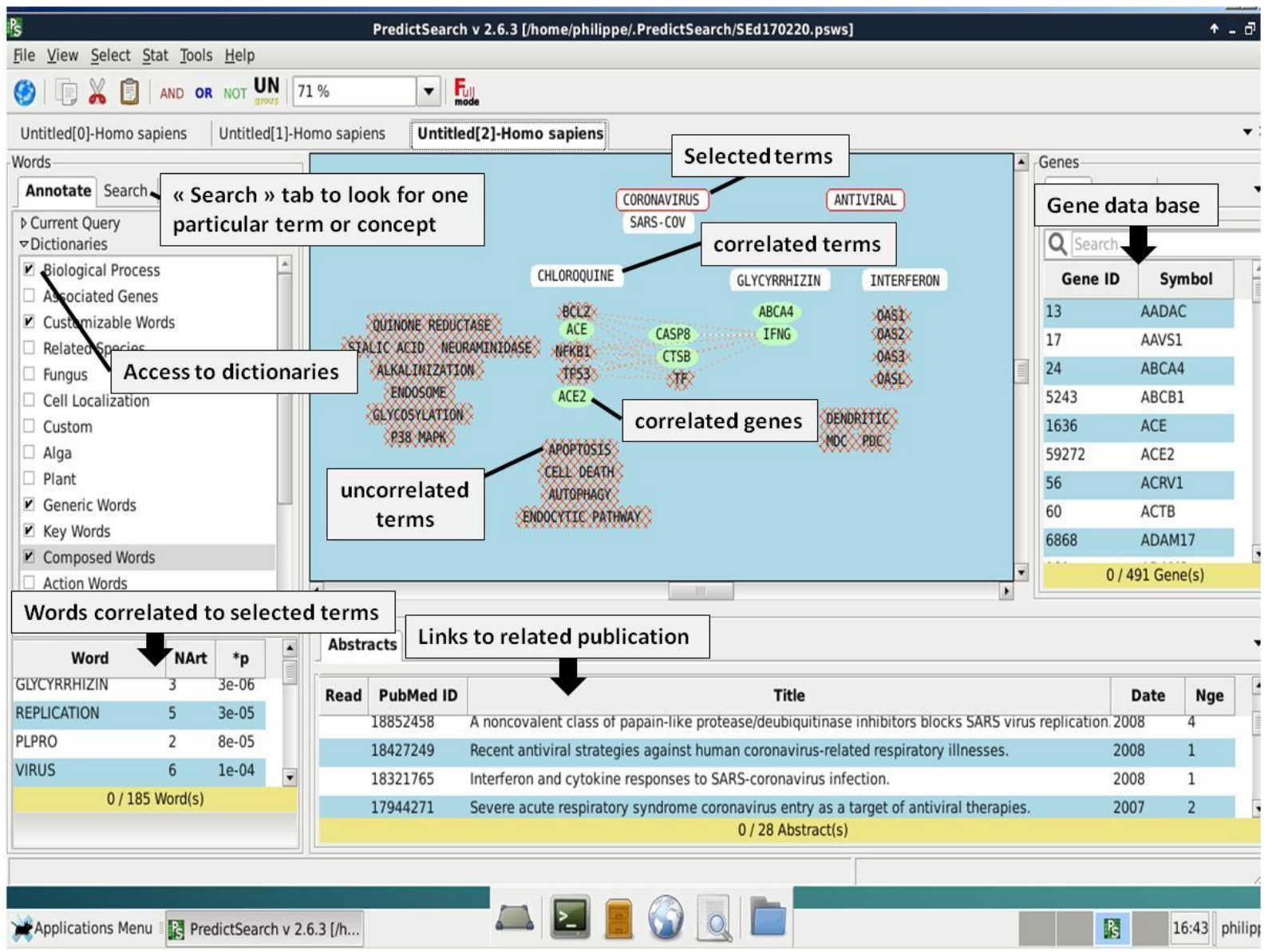


Figure 2

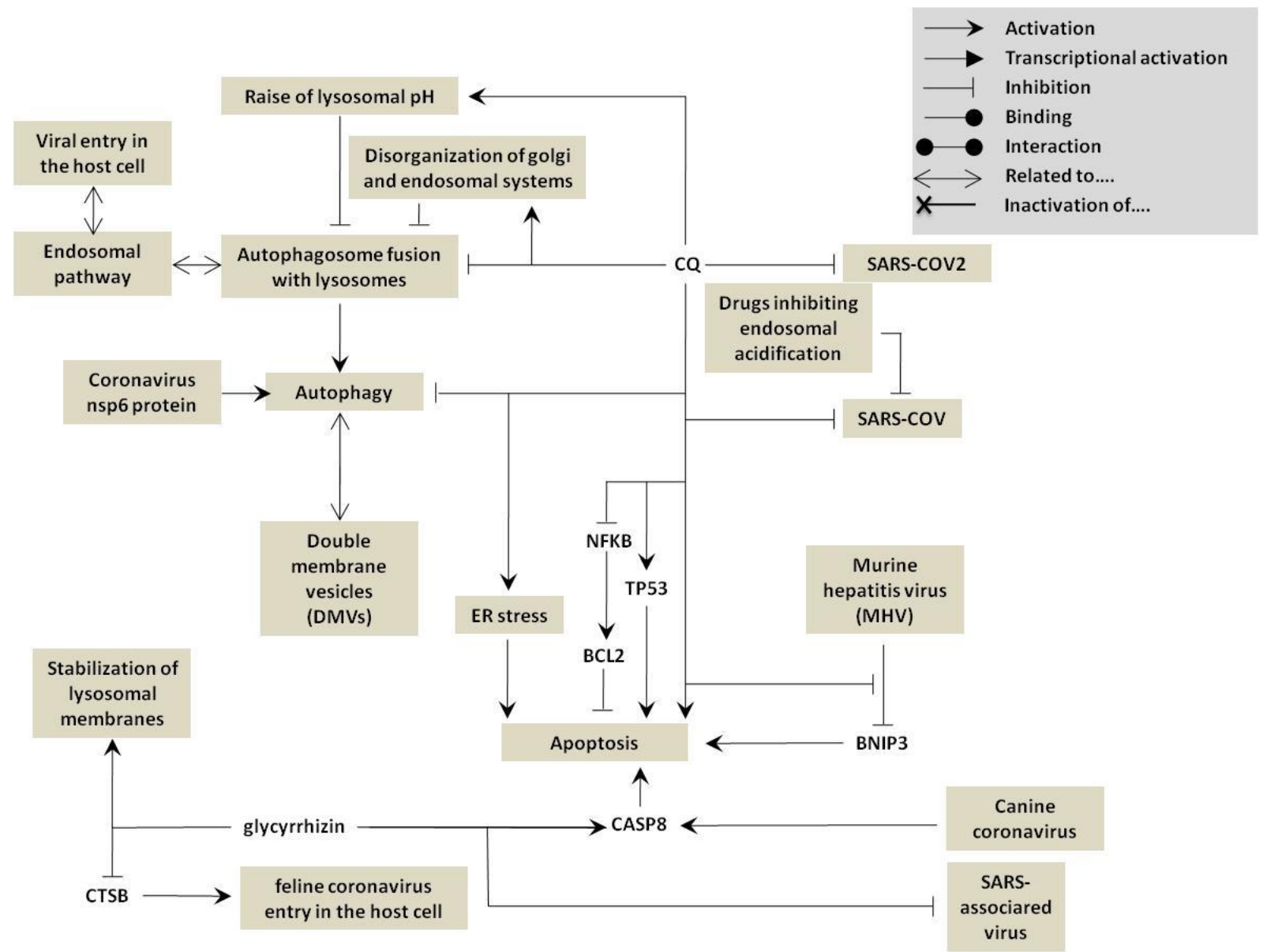


Figure 3

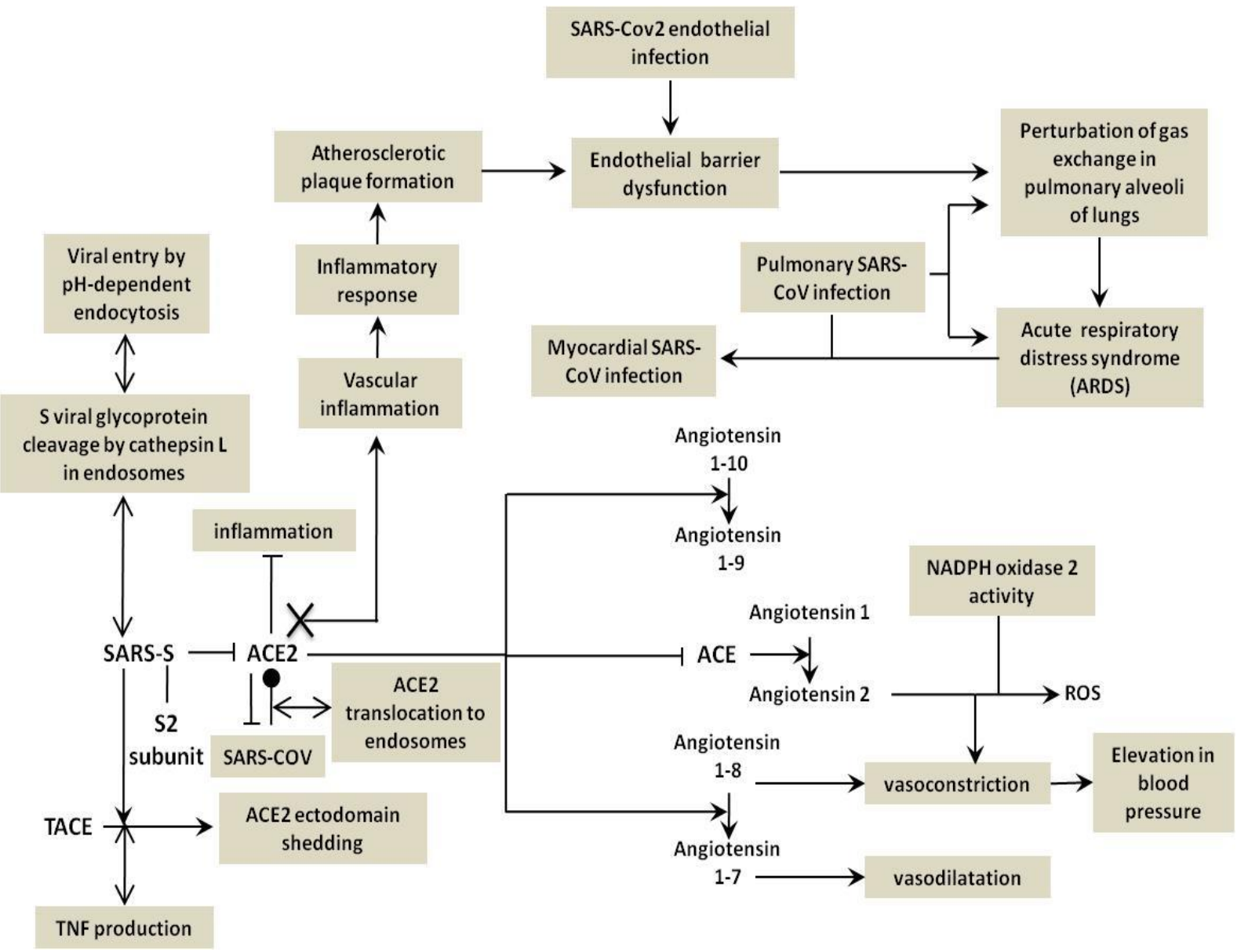




\section{Figure 4}

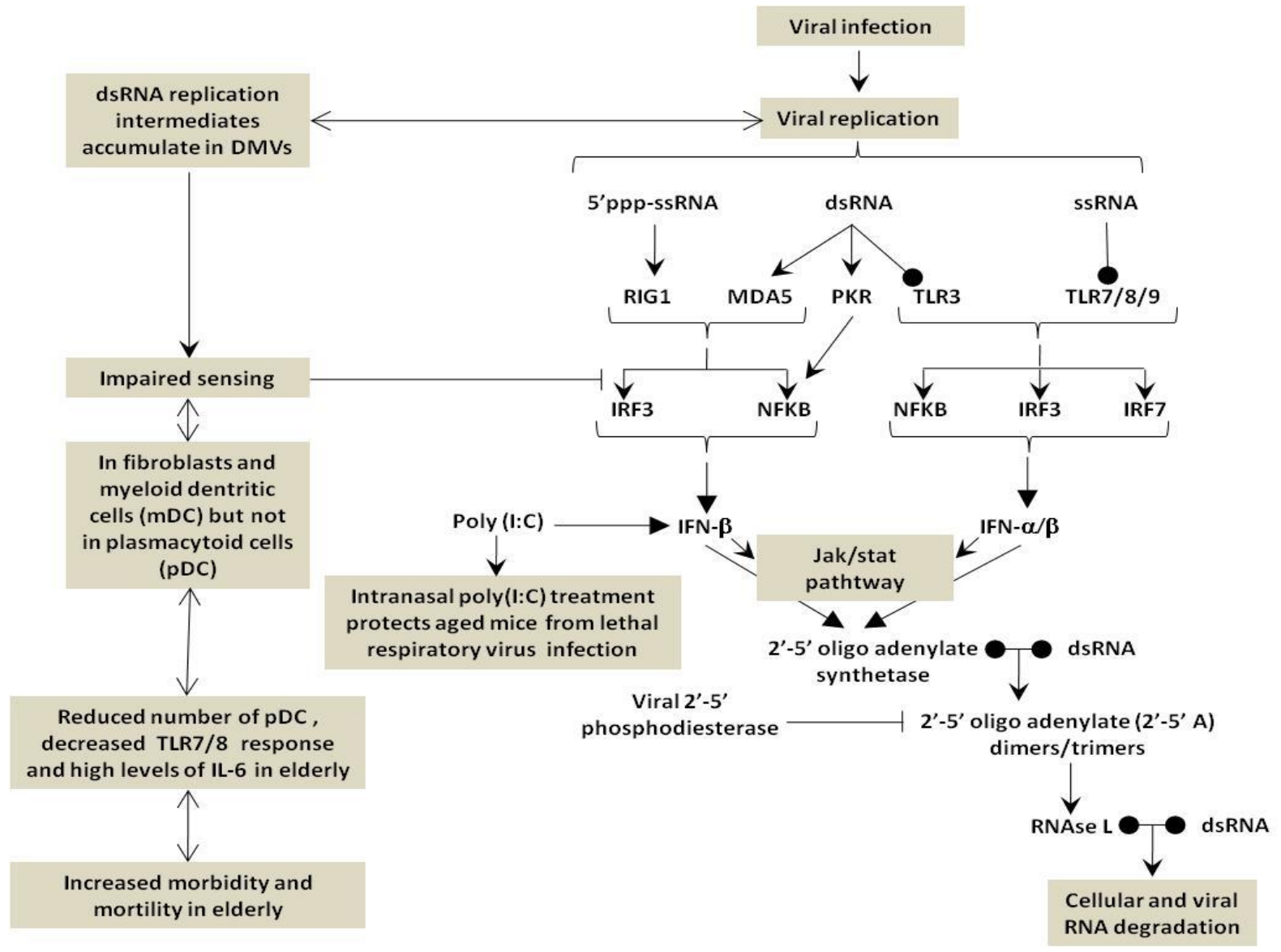

